\title{
TRAIL MAKING AND COGNITIVE SET-SHIFTING
}

\author{
RICARDO DE OLIVEIRA-SOUZA ', JORGE MOLL ${ }^{2}$, LEIGH J. PASSMAN ${ }^{3}$, \\ FERNANDO CIMINI CUNHA ${ }^{4}$, FLÁVIA PAES ${ }^{5}$, MARCUS VINICIUS ADRIANO ${ }^{6}$, \\ FÁTIMA AZEVEDO IGNÁCIO ${ }^{7}$, ROGÉRIO PAYSANO MARROCOS ${ }^{\circ}$
}

\begin{abstract}
We tested the hypothesis that Part B of the Trail Making Test (TMT) is a measure of cognitive setshifting ability in 55 normal subjects with the conventional (written) TMT and a verbal adaptation, the "verbal TMT" (vTMT). The finding of a significant association between Parts B of TMT and vTMT $(r=0,59, p<$ 0,001 ), after correcting for age and education, supports the view that Part B of TMT is a valid measure of the ability to alternate between cognitive categories.
\end{abstract}

KEY WORDS: trail making test, verbal trail making test, set-shifting cognition.

\section{Teste de trilhas e alternância cognitiva}

RESUMO - A hipótese de que a Parte $B$ do Teste de Trilhas contém um fator de alternância cognitiva independente das dimensões visuoperceptivas e visuomotoras foi testada em 55 indivíduos normais com as Partes A e B do Teste de Trilhas e uma adaptação falada, o "Teste de Trilhas Verbal". A verificação de correlação significante entre os formatos escrito e falado da Parte B do teste $(r=0,59, p<0,001)$, independente de idade e instrução, favorece a hipótese de que a Parte B do Teste de Trilhas constitui medida legítima da capacidade de alternar entre categorias cognitivas.

PALAVRAS-CHAVE: teste de trilhas, teste de trilhas verbal, cognição, desempenho cognitivo.

The Trail Making Test (TMT) is widely employed in the diagnosis of brain damage by clinical neuropsychologists ${ }^{1}$. It consists of two parts in which 25 circles containing numbers (Part A) or numbers and letters (Part B) must be sequentially connected ${ }^{2}$. In Part A, the circles are numbered from 1 to 25, whereas in Part B numbers from 1 to 13 and letters from A to M must be connected in alternating fashion, beginning at 1-A and ending at M-13. Total score is given by time spent to complete each part. Factor analysis has shown that the TMT loads on both a rapid visual search and a visuospatial sequencing factor ${ }^{3}$. Whether it also superimposes on a third, "cognitive set-shifting", factor has been debated ${ }^{4-6}$. If true, however, this would be an important attribute of the test, as the ability to switch between categories is one of the most reliable indexes of normal neurobehavioral functioning ${ }^{7}$.

In this study we administered a verbal adaptation of TMT - the "verbal Trail Making Test" (vTMT) — to normal individuals to see whether Part B of Trail Making Test (TMTB) also gauges the ability to shift between cognitive sets. Since in vTMT the visuospatial and visuomotor factors intrinsic to the conventional (written) TMT are reduced to a minimum, a lack of correlation between Parts B

${ }^{1}$ Neurologista, Grupo de Neuroimagem e Neurologia do Comportamento (GNNC)—LABS/Rede D'Or and Hospital Universitário Gaffrée e Guinle (UNI-Rio); ${ }^{2}$ Neurologista, GNNC—LABS/Rede D'Or; ${ }^{3}$ Assistant Professor, UCLA School of Medicine, USA; ${ }^{4}$ Graduação médica, Hospital Universitário Gaffrée e Guinle (UNIRio); ${ }^{5}$ Graduação em Psicologia, Instituto Brasileiro de Medicina e Reabilitação; ${ }^{6}$ Residente em Neurologia, Instituto de Neurologia Deolindo Couto, Universidade Federal do Rio de Janeiro (UFRJ); ${ }^{7}$ Psicóloga, Instituto Philippe Pinel, Rio de Janeiro; ${ }^{~}$ Psiquiatra, Instituto Philippe Pinel, Rio de Janeiro. Aceite: 24-maio-2000.

Dr. Ricardo de Oliveira Souza - Rua General Belford 226 - 20961-000 Rio de Janeiro RJ - Brasil. 
of TMT and vTMT would support the null hypothesis that performance on TMTB is mainly determined by visuomotor factors. Conversely, a significant association would indicate that setshifting is relevant to normal performance on the TMT.

\section{METHOD}

Fifty-five normal volunteers ( 23 males and 32 females), ages 18 to 73 (mean $=38 \pm 14$ years) participated in the study. Their level of formal education ranged from 4 to 18 years (mean $=14 \pm 3$ years), and only four did not complete high school. They were administered the $\mathrm{TMT}^{2}$ and the vTMT. Part B of both TMT and vTMT ended in M-13, since the Portuguese alphabet lacks the letter K.

Global cognitive status and socio-occupational level were assessed with the Mini-Mental State Exam (MMSE) ${ }^{8}$ and the Global Assessment of Functioning Scale (GAF) ${ }^{9}$, respectively.

\section{Procedure}

We asked each subject to count out loud from 1 to 25 (vTMTA) and to alternate between numbers and letters from 1-A to M-13 (vTMTB) as quickly as possible. The TMT was administered according to standard guidelines ${ }^{2}$. Presentation of TMT and vTMT was counterbalanced across individuals to eliminate order effects. The main metric of performance was time spent (in seconds) to complete Parts A and B of TMT and vTMT.

\section{Statistical analyses}

Pearson's correlation coefficients $(r)$ were computed for continuous variables of interest. Since age and education correlated significantly with both parts of TMT and vTMT, partial correlation coefficients adjusting for age and education were computed for Parts A and B of TMT and vTMT ${ }^{10,11}$. The power of the correlation coefficients were also computed ${ }^{12}$. A 0.05 level of significance was set for all correlations.

Table 1. Raw scores of performance on TMT and vTMT.

\begin{tabular}{lcc}
\hline & & Mean \pm sd (seconds) \\
\hline TMT & A & $30 \pm 11$ \\
& B & $66 \pm 32$ \\
vTMT & A & $7 \pm 2$ \\
& B & $25 \pm 18$ \\
\hline
\end{tabular}

Table 2. Pearson's correlation coefficients between TMT and $v T M T, M M S E$, and GAF, after partialling out the effects of age and instruction

\begin{tabular}{lcccc}
\hline & TMTA & TMTB & vTMTA & vTMTB \\
\hline TMTA & & & & \\
TMTB & $0.56^{\mathrm{a}}$ & & & \\
vTMTA & -0.10 & $0.58^{\mathrm{a}}$ & & \\
vTMTB & $0.44^{\mathrm{a}}$ & $0.59^{\mathrm{a}, \mathrm{b}}$ & 0.06 & \\
MMSE & -0.14 & $-0.54^{\mathrm{a}}$ & 0.10 & -0.14 \\
GAF & -0.07 & -0.28 & $-0.39^{\mathrm{a}}$ & -0.16 \\
\hline
\end{tabular}




\section{RESULTS}

The main results are shown in Tables 1 and 2. As expected, it took more time to complete Part B than Part A of both TMT and vTMT. Of immediate relevance to our hypothesis was the finding of a correlation of 0.59 between the written and spoken formats of Part B, with a statistical power close to 1 . Significant correlations were also found for TMTB with vTMTA, vTMTB, and the MMSE. Gender did not influence performance on any variable.

\section{DISCUSSION}

This study found a powerful correlation between TMTB and vTMTB, which persisted after correction for age and education. Such findings are consistent with the idea that, in comparison to TMTA, normal performance on TMTB depends on additional cognitive factors. We believe that this factor is best explained by a cognitive set-shifting mechanism, which is so evident during routine execution of both TMTB and VTMTB. It is possible that, in real life, cognitive operations analogous to those recruited during performance of TMT are active in situations demanding quick behavioral adjustments to the environment. However, the relationship between TMTB/vTMTB and activities of daily living is still open to emprirical testing.

Ricker and Axelrod ${ }^{13}$ found equally strong associations between TMT and vTMT in 58 normal individuals. In contrast to them, however, we found no association between TMTA and vTMTA, a result possibly related to the broader age range of their sample.

In a recent study with functional magnetic resonance imaging on the cerebral correlates of vTMTB in normal subjects, we found that most activations concentrated in the inferior frontal gyrus and sulcus, angular gyrus, and medial frontal cortex of the left hemisphere ${ }^{14}$. These areas are part of a neural network implicated in the adjustment of the degree of attentional effort to task demands in circumstances requiring rapid action ${ }^{15}$ or cognitive $^{16}$ shifts. Functional neuroimaging studies have shown that the ability to switch between cognitive sets during Wisconsin Card Sorting Test performance, another task often employed to tap set-shifting mechanisms ${ }^{17,18}$, is also related to activation in the rostral third of the inferior frontal sulcus ${ }^{19}$.

The verbal paradigm of the TMT offers another approach to probe the existence of a setshifting dimension of TMTB performance in normal individuals. As such, it adds to findings derived from factor analyses ${ }^{4}$ and from adaptations of the classic format of the $\mathrm{TMT}^{5}$. Its clinical utility, however, remains to be confirmed ${ }^{20,21}$.

Acknowledgments - The authors are indebted to Professor Omar da Rosa Santos (Head of the Service of General Medicine, Hospital Gaffrée e Guinle, UNI-Rio) for supporting this work. They are also indebted to the peer reviewers for their invaluable suggestions to the manuscript.

\section{REFERENCES}

1. Butler M, Retzlaff P, Vanderploeg R. Neuropsychological test usage. Professional Psychology: Research and Practice 1991;22:510-512.

2. Reitan RM. Validity of the Trail Making Test as an indicator of organic brain damage. Percept Mot Skills 1958;8:271-276.

3. Fossum B, Holmberg H, Reinvang I. Spatial and symbolic factors in performance on the Trail Making Test. Neuropsychology 1992;6:71-75.

4. Crowe SF. The differential contribution of mental tracking, cognitive flexibility, visual search, and motor speed to performance on Parts A and B of the Trail Making Test. J Clin Psychol 1998;54:585-591.

5. Gaudino EA, Geisler MW, Squirees NK. Construct validity in the Trail Making Test: what makes Part B harder? J Clin Exp Neuropsychol 1995;17:529-535.

6. Pontius AA, Yudowitz BS. Frontal lobe dysfunction in some criminal actions as shown in the Narratives Test. J Nerv Ment Dis 1980;168:111-117.

7. Freeman T, Gathercole CE. Perseveration ${ }^{-}$the clinical symptoms`in chronic schizophrenia and organic dementia. $\mathrm{Br} \mathbf{J}$ Psychiatry 1966;112:27-32.

8. Folstein MF, Folstein SE, McHugh PR. "Mini-Mental State": a practical method for grading the cognitive state of patients for the clinician. J Psychiat Res 1975;12:189-198.

9. American Psychiatric Association: Diagnostic and statistic manual of mental disorders, 4Ed. (DSM-IV). Washington, DC: American Psychiatric Association, 1994. 
10. Welkowitz J, Ewen RB, Cohen J. Introductory statistics for the behavioral sciences, 4Ed. Fort Worth: Harcourt Brace Jovanovich 1991.

11. Kachigan SK. Statistical analysis: an interdisciplinary introduction to univariate and multivariate methods. New York: Radius Press, 1986.

12. Cohen J. Statistical power analysis for the behavioral sciences, 2Ed. Hillsdale, NJ: Lawrence Erlbaum Associates, 1988.

13. Ricker JH, Axelrod BN. Analysis of an oral paradigm for the Trail Making Test. Assessment 1994;1:47-51.

14. Moll J, Oliveira-Souza R, Bramati I, Paes F, Cunha FC, Adriano MV. Functional imaging of set alternation: a fMRI study of a modified version of the Trail Making Test. Hum Brain Mapp (in press).

15. Moll J, Oliveira-Souza R, Passman LJ, Cunha FC, Lima FS, Andreiuolo PA. Functional magnetic resonance imaging of pantomimes of tool use. Neurology 2000;54:1331-1336.

16. Carter CS, Braver TS, Barch DM, Botvinick MM, Noll D, Cohen JD. Anterior cingulate cortex, error detection, and online monitoring of performance. Science 1998;280:747-749.

17. Heaton RK, Chelune GJ, Talley JL, Kay GG, Curtiss G. Wisconsin Card Sorting Test manual. Odessa, FL: Psychological Assessment Resources, 1993.

18. Oliveira DLG, Oliveira-Souza R, Cunha FC, Moll J, Marrocos RP. Dysexecutive amnesia syndrome in neuropsychiatric disorders: the effect of breaking the codes of the Wisconsin Card Sorting Test. Neurology 1999;52(Suppl 2):A490.

19. Konishi S, Nakajima K, Uchida I, et al.. Transient activation of inferior prefrontal cortex during cognitive set shifting. Nature Neurosci 1999;1:80-84.

20. Abraham E, Axelrod BN, Ricker JH. Application of the Oral Trail Making Test to a mixed clinical sample. Arch Clin Neuropsychol 1996;11:697-701.

21. Ricker JH, Axelrod BN, Houtler BD. Clinical validation of the oral Trail Making Test. Neuropsychiatry Neuropsychol Behav Neurol 1996;9:50-53. 